\title{
The use of response measures in meta-analyses of land-use impacts on ecological communities: a review and the way forward
}

\author{
Anne-Maarit Hekkala ${ }^{1}$ D Jean-Michel Roberge ${ }^{1,2}$ (D)
}

Received: 8 January 2018 / Revised: 30 May 2018 / Accepted: 12 June 2018 / Published online: 19 June 2018 (c) The Author(s) 2018

\begin{abstract}
Species richness and total abundance are two of the most commonly used response measures in empirical studies of the effects of anthropogenic land-use on biodiversity, in spite of the fact that they are insensitive to changes in a range of community attributes. We evaluated the extent to which meta-analyses about the effects of forest land-use on ecological communities make use of gross species richness, diversity and abundance measures (hereafter low-informative measures) as opposed to more refined response variables conveying a higher degree of conservation-relevant information, e.g., by accounting for compositional or functional changes in the communities (high-informative measures). Nearly one-half of the 221 included meta-analyses were based solely on low-informative measures. The prevalence of low-informative measures was higher for meta-analyses belonging to studies encompassing a broad taxonomic scope and it has increased since 2002. Few differences were detected in the use of response measures among taxonomic groups, although there were indications that some better-known groups tended to be more often studied with high-informative measures. To provide guidance for future work, we synthesized the highinformative measures of biodiversity used in the reviewed studies. For better-informed meta-analyses, we encourage the use of more refined approaches to quantify impacts on communities in addition to species richness and total abundance measures. This may involve, for example, the use of $\beta$ diversity and functional diversity measures, as well as separate analyses for different ecological groups or conservation status categories.
\end{abstract}

Keywords Community structure $\cdot$ Diversity $\cdot$ Ecological groups $\cdot$ Functional diversity · Species traits $\cdot$ Land-use change

Communicated by David Hawksworth.

Electronic supplementary material The online version of this article (https://doi.org/10.1007/s1053 1-018-1583-1) contains supplementary material, which is available to authorized users.

Anne-Maarit Hekkala

anne.maarit.hekkala@slu.se

1 Swedish University of Agricultural Sciences (SLU), Department of Wildlife, Fish and Environmental Studies, 90183 Umeå, Sweden

2 Present Address: Swedish Forest Agency, Box 284, 90106 Umeå, Sweden 


\section{Introduction}

An increasingly used analytical approach in conservation science is to synthesize the results of several primary studies through meta-analyses (Gurevitch et al. 2018). Metaanalyses often have high scientific and social impact, especially in applied science, where different stakeholders may not have the time or expertise to read through the plethora of original studies (Koricheva et al. 2013). However, meta-analyses pose a number of challenges (Koricheva et al. 2013; Lortie et al. 2015). One is to choose a relevant and meaningful response measure to synthesize the effect of the treatment or action of interest. Inevitably, the choice of the response measure will be at least partly dictated by the measures used in the primary studies included in the meta-analysis.

Substantial amounts of information addressing the effects of anthropogenic land-use on biodiversity have been gathered over the years, allowing increasing numbers of meta-analyses. However, measuring biodiversity is not an easy task and the choice of measures may affect the interpretation of the change in biodiversity and hence, prioritization of resources for conservation (Magurran 2004; Chiarucci et al. 2011; Santini et al. 2017). Taxonomic richness of communities (e.g., local species richness) along with total community abundance (e.g., the total number of individuals in a community) are two of the most commonly used biodiversity measures in empirical studies addressing land-use impacts (Balvanera et al. 2006; Dornelas 2010; Vellend et al. 2013). This is in spite of the fact that species richness is insensitive to changes in a range of community attributes, such as changes in species composition (Supp and Ernest 2014; Lindenmayer et al. 2015). Moreover, species richness, diversity (i.e., combined measures of species richness and evenness) and total abundance do not account for functional, evolutionary or ecological differences among species (Chiarucci et al. 2011; Cadotte et al. 2011). Specialist species might be replaced by generalists, species of conservation concern may be substituted by common or invading species and ecosystem functionality may deteriorate, while species richness or total community abundance may remain constant or even increase (Cadotte et al. 2011). Using more refined measures of community structure (accounting e.g., for taxon-specific abundance or species turnover) can yield much deeper insight compared to total species richness or total abundance measures (Barlow et al. 2007; Jaunatre et al. 2013; Dornelas et al. 2014; Supp and Ernest 2014; Shimadzu et al. 2015). When the ecologies of the focal study organisms are well known, species can be divided into ecologically relevant groups according to e.g., habitat or resource requirements, foraging behaviour, growth form or ecological functions, thereby increasing our understanding of the impacts of anthropogenic actions on biodiversity and thus providing more conservation-relevant information (Gerisch et al. 2012; Lindenmayer et al. 2015). Similarly, species can be grouped by their conservation concern, where applicable, according to e.g., endemism or red list status, enhancing our knowledge about the conservation implications of the studied anthropogenic actions. However, facing a need for a sufficient sample of primary studies, meta-analysts will often have no choice but to use the response measures that are most commonly used in the field. Considering the widespread use of gross species richness and total community abundance as response measures in conservation ecology research (e.g. Balvanera et al. 2006), there is an obvious risk that these overly simplistic response measures will be frequently used for meta-analyses.

We assessed the extent to which meta-analyses about the effects of anthropogenic landuse on ecological communities in forested ecosystems make use of gross species richness and abundance measures as opposed to more refined response measures conveying 
more conservation-relevant information. We focused on forests as a focal system because of the unique importance of the world's forests to terrestrial biodiversity and due to the large number of published studies about the ecological effects of forest management, but we believe that our findings will apply also on other terrestrial and aquatic systems. We classified the meta-analyses into three categories: (1) meta-analyses based on low-informative measures with or (2) without taxonomic refinement, or (3) meta-analyses based on high-informative measures, based on the information contained in the metrics they used to quantify the effects of anthropogenic actions. We also assessed whether the use of the lowinformative measures has varied over time and explored trade-offs between information contained in the measures and the geographical scale and breadth of the study's taxonomic scope. Here, we hypothesized that studies with a broad geographical or taxonomic scope are more likely to restrict themselves to basic low-informative measures due to constraints related to the number of analyses that can be presented in a paper, and to the larger amounts of knowledge which are required for implementing more refined measures (e.g., knowledge of species' ecologies or conservation status) to broader datasets. Furthermore, we evaluated potential differences in the use of measures among taxonomic groups, hypothesizing that low-informative measures would be less prevalent in well-known broad taxonomic groups (e.g., vertebrates, plants) than in lesser-known groups (e.g., invertebrates, fungi). To provide guidance for improving the choice of response measures both in primary studies and meta-analyses, we finally synthesized the high-informative approaches presented in the reviewed literature.

\section{Methods}

\section{Literature search and data extraction}

We searched the ISI Web of Science Core Collection for relevant studies with the search string $\mathrm{TS}=(($ meta-analy* OR metaanaly* OR meta analy*) AND (forest* OR woodland* OR plantation* OR agroforest* OR agro-forest*) AND (biodivers* OR divers* OR rich* OR assembl* OR communit* OR compos* OR structur* OR abund* OR cover* OR densit*)). We performed the search in January 2017, and set the latest publication date to the end of year 2016 (31.12.2016). No limit was set for the first publication year. The search yielded 917 studies that we screened for relevance by reading the title and abstract.

To be included in our evaluation, a study had to be published in a peer-reviewed journal and fulfill the following criteria:

(1) The study had to present one or many meta-analyses. Herein, we define a meta-analysis as an analysis that summarizes the results of at least two independent primary studies and includes a statistical analysis of strength of evidence across studies (Koricheva et al. 2013; Lortie et al. 2015).

(2) The meta-analysis had to address anthropogenic impacts on communities of at least five multicellular species. We restricted ourselves to measures focusing on the occurrence of species and/or their constituent individuals. Hence, we excluded analyses solely addressing behavior, performance, or species interactions.

(3) The meta-analysis had to address a question related to how an anthropogenic action affects biodiversity or conservation goals or species communities comprising biodiversity. Hence we excluded studies concentrating on e.g., management actions to 
improve solely yield (e.g., timber production), unless yield was used as a surrogate of biodiversity after e.g., restoration.

(4) All or at least some of the primary studies underlying the meta-analysis had to be performed in forested landscapes. Meta-analyses restricted entirely to non-forest environments (e.g., grasslands, shrublands, aquatic systems) were excluded.

After title and abstract screening, we read 164 studies by full text. Of these, we omitted 75 studies because they did not fulfill the inclusion criteria above, yielding a final set of 89 studies. Fifty percent of the included studies presented separate analyses for different taxonomic groups (i.e., different study objects at the level of subgroups; see below). Hereafter, we treat these taxonomically restricted meta-analyses as the units of replication in our analyses.

We extracted the following data from each of the included meta-analyses: year of publication of the study, study object(s) and geographical scale. We defined study objects using the following broad taxonomic groups and subgroups (in parentheses): 'vertebrate animals' (mammals, birds, amphibians, reptiles, herpetofauna [when amphibians and reptiles were pooled]), 'invertebrate animals' (arachnids, insects, other/unspecified invertebrates), 'plants' (vascular plants, non-vascular plants), 'fungi' (fungi, lichens), and finally 'unspecified' (fauna, flora, fauna \& flora) for the study objects that did not exclusively fit into any of the above groups (i.e., pooled two or several groups in the analyses). We categorized the geographical scale of the study as 'within-continent' or 'intercontinental' depending on where the data were collected from. We also classified the meta-analyses according to the number of study objects addressed by the paper (hereafter 'taxonomic scope'), we used the term 'narrow' when only one study object (at the level of subgroups listed above) was addressed, and 'wide' when two or more objects were simultaneously addressed.

\section{Evaluation of the response measures used in meta-analyses}

We analyzed the meta-analyses based on the information contained in the response variables that they used to summarize anthropogenic impacts in terms of the ecological implications of the results from an applied conservation perspective. To structure the analysis, we grouped the response measures into three categories: 'low-informative without taxonomic refinement', 'low-informative with taxonomic refinement' and 'high-informative'. We categorized measures as 'low-informative' if they only accounted for total species richness, overall inventory diversity (e.g., $\alpha$-diversity; Whittaker et al. 2001) or total abundance. We used the category 'low-informative without taxonomic refinement' to depict low-informative measures pertaining to the taxonomic level of class or higher, and the category 'lowinformative with taxonomic refinement' to depict studies where additional analyses were performed separately for different taxonomic groups defined at a level lower than class. We categorized measures as high-informative whenever they accounted for differentiation diversity (Jurasinski et al. 2009) ( $\beta$ diversity, differences in community structure, community turnover) or functional diversity, richness and/or abundance of species belonging to particular functional or ecological groups, abundance of the individual species comprising the community, or effects on species of special conservation concern (Fig. 1 and Online Resource 1). We acknowledge that there is a more or less continuous gradient in the conservation relevance of the information conveyed by the meta-analyses. Hence, any such categorization is arbitrary by nature. Still, we believe that our categories offer a useful systematic benchmark for analyzing the types of response measures used in the meta-analyses. 


LOW-INFORMATIVE WITHOUT TAXONOMIC REFINEMENT
The meta-analysis is based on the following measures only:
Total species richness, inventory diversity or abundance
for the focal species group, or for different groups predefined at the level of class or higher
LOW-INFORMATIVE WITH TAXONOMIC REFINEMENT
The meta-analysis in based on the following measures only:
Species richness, inventory diversity or abundance broken down into two or more taxonomic groups
below the class level (e.g. orders or families)
HIGH-INFORMATIVE
The meta-analysis is based on at least one of the following measures:
Assemblage composition or structure
e.g. $\beta$ diversity measures
Species richness, diversity or abundance separately for groups of particular conservation concern
e.g. red-listed species
Species richness, diversity or abundance separately for different functional or ecological groups
e.g. feeding groups
Functional diversity or composition
e.g. functional richness, diversity or divergence
Tracked abundances of the individual species comprising the assemblage

Fig. 1 Evaluation criteria for response measures. Summary of the categories used for classifying the metaanalyses based on the measures they use to synthesize anthropogenic actions on biodiversity. A detailed description of the criteria is provided in Online Resource 1

Moreover, we want to stress that our assessment of the informativeness of the response measures (from a conservation perspective) does not imply any judgement about the quality of the studies as such: a meta-analysis based on a low-informative measure may still hold high scientific quality given the specific questions addressed in the paper.

\section{Data analysis}

The 89 retained studies included 221 meta-analyses of separately reported taxonomic subgroups (see above for subgroup definitions). To evaluate whether meta-analyses focusing on different broadly defined taxonomic groups (vertebrates $[n=112]$, invertebrates [43], plants [26], fungi [15] and unspecified [25]), geographical scales (within-continent [91]/ intercontinental [130]) or belonging to studies having different breadths of taxonomic scopes (narrow [44]/wide [177]) differed in their probability to use low-informative measures, or whether the proportion of meta-analyses using low-informative measures was related to publication year, we fitted general linear mixed models (GLMM) with a binomial error structure (lme4, Bates et al. 2015). Due to possible dependencies between explanatory variables and considering the exploratory nature of the analyses, we evaluated the influence of the different variables separately in univariate models. Here, the binomial response was whether a meta-analysis used a low-informative (with or without taxonomic refinement) as opposed to a high-informative response measure. We opted for this binary approach (pooling the two categories of low-informative measures) because low-informative measures with taxonomic refinement were rare (see "Results"). To address the dependency in the dataset that arises from multiple meta-analyses belonging to the same study (i.e., publication), we added study ID as a random factor in the GLMMs. We also fitted 
an equivalent GLMM to evaluate whether there were differences in the prevalence of lowinformative measures between taxonomic subgroups within the broader taxonomic groups. In the models, we included only taxonomic subgroups with $n \geq 10$. The fulfilment of the model assumptions were checked with diagnostic residual plots. All the analyses were performed in R 3.2.3. (R Development Core Team 2015).

\section{Results}

An overwhelming majority (82\%) of the studies were published between 2010 and 2016, and none before 2002 (Online Resource 2), illustrating the strong recent increase in the use of meta-analyses to synthesize studies exploring the effects of anthropogenic actions on biodiversity in forested environments. In total, nearly one-half (49\%) of the 221 meta-analyses were based only on low-informative measures (2\% with and $47 \%$ without taxonomic refinement).

The prevalence of low-informative measures (with or without taxonomic refinement) was much higher for meta-analyses belonging to studies with a wide taxonomic scope (i.e., addressing at least two taxonomic subgroups) (55\%) compared to studies having a narrow taxonomic scope (26\%) (Table 1). The proportion of meta-analyses based on low-informative measures was similar in intercontinental studies and in studies conducted within one continent (47 and 51\%, respectively, Table 1). The prevalence of meta-analyses based on low-informative measures increased significantly with time (Table 1).

No significant differences were detected in the use of response measures among the broad taxonomic groups (Table 2, Fig. 2). However, there was a near-significant trend whereby fungi were more often studied with low-informative measures $(67 \%)$ than vertebrates (45\%) and unspecified taxa (44\%) (Table 1). In invertebrates and plants the share of meta-analyses using low-informative measures was approximately one-half (54 and 50\%, respectively).

Table 1 Results of generalized linear mixed models explaining the proportion of meta-analyses using lowinformative biodiversity response measures

\begin{tabular}{llrlrl}
\hline Model formula $^{\mathrm{a}}$ & Explanatory variable & Estimate & $\mathrm{SE}$ & $\mathrm{Z}$ & $\mathrm{P}^{\mathrm{b}}$ \\
\hline Model 1: $\mathrm{y} \sim$ broad taxonomic group & Fungi (intercept) & 0.8972 & 1.1730 & 0.765 & 0.4443 \\
& Invertebrates & -1.3671 & 1.1995 & -1.140 & 0.2544 \\
& Plants & -1.3004 & 1.2869 & -1.010 & 0.3122 \\
& Unspecified & -2.1840 & 1.4825 & -1.473 & 0.1407 \\
& Vertebrates & -2.2609 & 1.2149 & -1.861 & 0.0627 \\
Model 2: y $\sim$ year & Intercept & $\mathbf{- 5 . 0 5 7 6}$ & $\mathbf{2 . 0 4 0 8}$ & $\mathbf{- 2 . 4 7 8}$ & $\mathbf{0 . 0 1 3 2}$ \\
& Year & $\mathbf{0 . 4 4 5 6}$ & $\mathbf{0 . 1 9 5 3}$ & $\mathbf{2 . 2 8 1}$ & $\mathbf{0 . 0 2 2 5}$ \\
Model 3: y $\sim$ breadth of the taxonomic & Narrow (intercept) & $\mathbf{- 2 . 7 4 5}$ & $\mathbf{1 . 0 7 3}$ & $\mathbf{- 2 . 5 5 9}$ & $\mathbf{0 . 0 1 0 5}$ \\
scope & Wide & $\mathbf{2 . 8 6 2}$ & $\mathbf{1 . 1 9 9}$ & $\mathbf{2 . 3 8 7}$ & $\mathbf{0 . 0 1 7 0}$ \\
Model 4: y $\sim$ geographical scale & Within-continent (intercept) & -1.1566 & 0.8392 & -1.378 & 0.168 \\
& Intercontinental & 0.4313 & 0.9414 & 0.458 & 0.647 \\
\hline
\end{tabular}

${ }^{a}$ Model formulas: glmer: $\mathrm{y} \sim \mathrm{x}+(1$ studyID $)$, family $=$ binomial, number of observations $=221$, number of groups $=89$

${ }^{\mathrm{b}}$ Significant effects $(P \leq 0.05)$ are given in bold and nearly significant effects $(0.05 \leq P \leq 0.1)$ in italics 
Table 2 Results of generalized linear mixed models comparing the proportion of low-informative biodiversity response measures among taxonomic subgroups within vertebrates and invertebrates

\begin{tabular}{|c|c|c|c|c|c|}
\hline Taxonomic group & Explanatory variable & Estimate & SE & $\mathrm{Z}$ & $\mathrm{P}^{\mathrm{c}}$ \\
\hline \multirow[t]{3}{*}{ Within vertebrates ${ }^{\mathrm{a}}$} & Amphibians (intercept) & 0.776 & 1.249 & 0.622 & 0.534 \\
\hline & Birds & -2.891 & 1.766 & -1.637 & 0.102 \\
\hline & Mammals & -1.613 & 1.384 & -1.165 & 0.244 \\
\hline \multirow[t]{2}{*}{ Within invertebrates ${ }^{\mathrm{b}}$} & Insects (intercept) & -11.390 & 2.935 & -3.881 & $<0.001$ \\
\hline & Unspecified invertebrates & 22.925 & 3.904 & 5.872 & $<0.001$ \\
\hline
\end{tabular}

${ }^{a}$ Model formula: glmer: $y \sim x+(1$ studyID), family $=$ binomial, number of observations $=94$, number of groups $=55$

${ }^{b}$ Model formula: glmer: $y \sim x+(1$ studyID $)$, family $=$ binomial, number of observations $=39$, number of groups $=36$

${ }^{\mathrm{c}}$ Significant differences $(P \leq 0.05)$ are given in bold

Only vertebrates and invertebrates had sufficient data for within-group testing. Among vertebrates, there were no significant differences among taxonomic subgroups (Fig. 2, Table 2). Among invertebrates, the proportion of meta-analyses based on low-informative measures was significantly higher within the category 'unspecified or other invertebrates' (the latter comprising non-insects and non-arachnids) (76\%) than within insects (20\%) (Fig. 2, Table 2).

Among the meta-analyses using high-informative measures, the most frequent approach (occurring in $68 \%$ of the meta-analyses based on high-informative measures) was to categorize species into ecological or functional groups based on habitat requirements, nativeness, foraging strategy, growth form or functions that the species perform in ecosystems (Fig. 3). Measures of $\beta$ diversity were used in $23 \%$ of the high-informative analyses. Individual species abundances and groupings based on levels of conservation concern were used as response measures in equal proportions (16\% each). Functional diversity was not used in any of the reviewed meta-analyses. Note that the proportions for the five categories of high-informative measures above do not sum to $100 \%$ because some studies have used several high-informative response measures.

\section{Discussion}

Our results show that nearly one-half of the meta-analyses focusing on the effects of anthropogenic actions on forest biodiversity have relied only on simplistic response measures that may give insufficient or even misleading descriptions of the changes occurring in ecological communities. In studies addressing several taxonomic groups simultaneously, a majority of the meta-analyses were based on low-informative measures. More alarmingly, the proportion of meta-analyses based on low-informative measures has been continuously increasing through time, in spite of the fact that several authors have acknowledged the limitations of species richness and total abundance as response measures (e.g., Anand et al. 2010; Putz et al. 2012; Duguid and Ashton 2013; Burivalova et al. 2014; Chaudhary et al. 2016). 

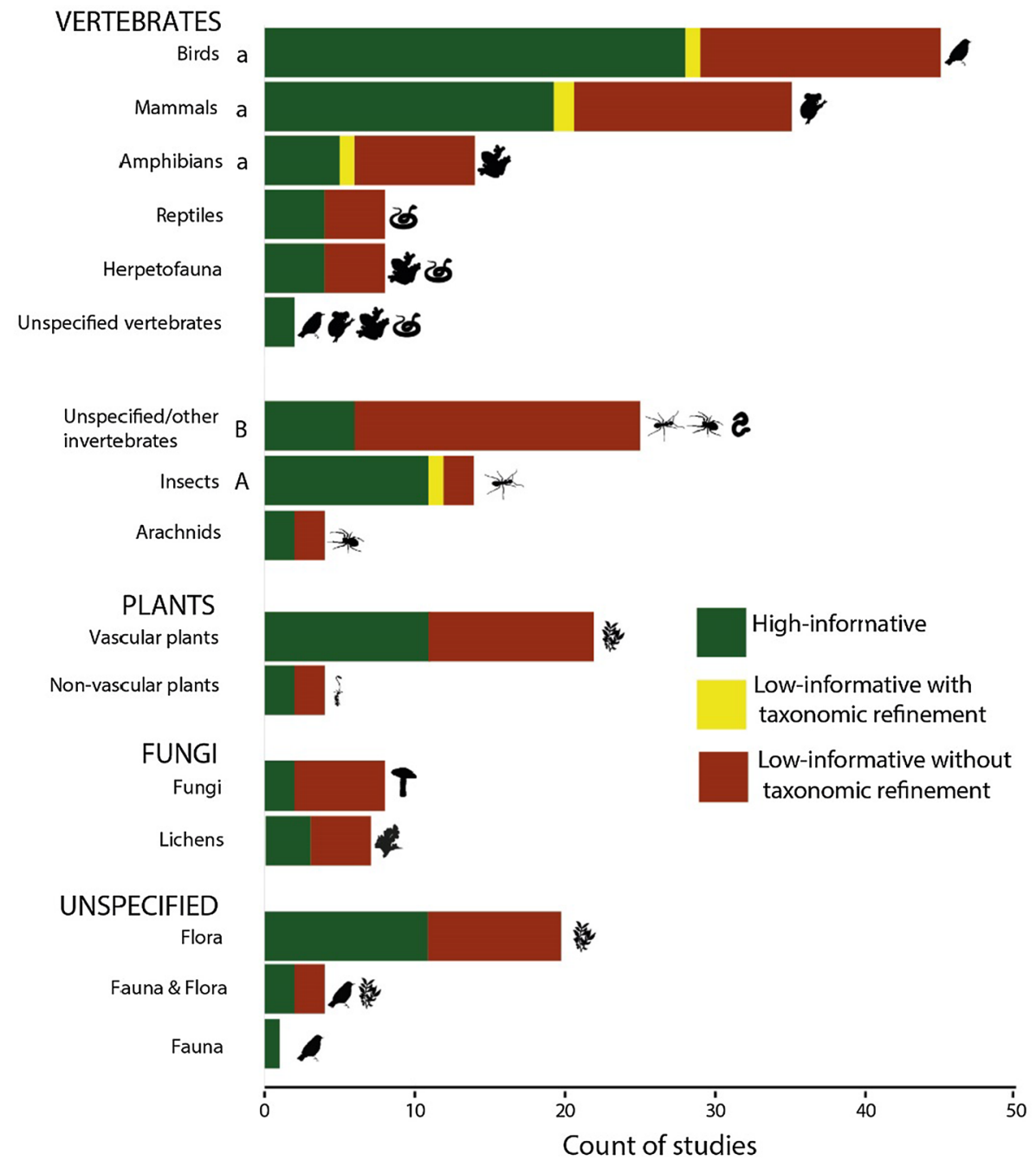

Fig. 2 Count of meta-analyses comprising different taxonomic groups and frequency of use of response measures. For each of the five broad taxonomic groups, data are presented for a number of taxonomic subgroups, where each study is represented only once per subgroup. The letters show the results of GLMMs testing for the differences in the proportion of meta-analyses based on low-informative measures among taxonomic subgroups (only those with $\mathrm{n} \geq 10$ ) within vertebrates (lowercase letters) and invertebrates (uppercase letters) (see Table 2). Different letters mean statistical significance $(\mathrm{P} \leq 0.05)$ in prevalence of low-informative measures

Although our evaluation was conducted only on a subset of all meta-analyses addressing biodiversity change, we believe that our findings showing a prevalence of low-informative biodiversity measures in forest environment likely apply to other ecosystems types. Indeed, forests are among the most studied ecosystems on earth, and the understanding of the drivers and factors constraining forest biodiversity should be 


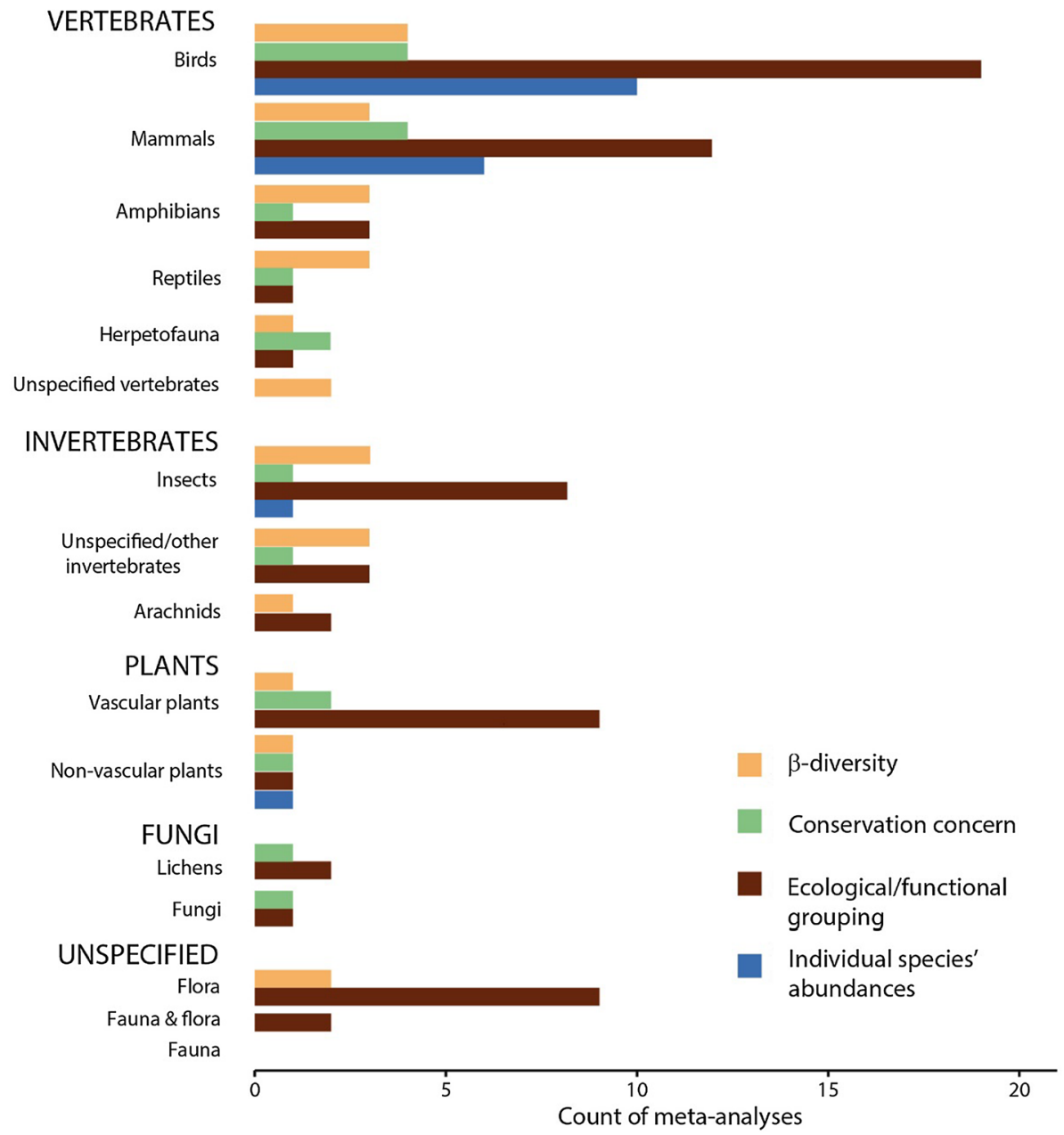

Fig. 3 Count of different high-informative measures and approaches used in meta-analyses to address the changes in biodiversity, presented by taxonomic subgroups. One study object (taxonomic subgroup) may have been assessed with several measures; thus the sum of the counts differs from those in Fig. 2. Note that functional diversity was not used in any of the reviewed studies; hence, it is not presented in the figure

relatively good there in comparison to e.g., marine systems (e.g., Murphy and Romanuk 2016).

\section{Potential factors influencing the prevalence of low- versus high-informative measures}

Contrary to our expectation, the prevalence of low-informative response measures did not seem to be influenced by the geographical scale of the studies. Instead, it was clearly related to the breadth of the taxonomic scope: there was a higher prevalence of low-informative measures in studies addressing several taxonomic groups, suggesting a trade-off 
between the breadth of the taxonomic scope and the information contained in the used measures. We can envisage at least three possible causes for that trade-off: (1) a strive for simplicity in the design and presentation of the studies (total species richness is straight forward measure that does not require much explanation compared to more complex measures of biodiversity); (2) space restrictions in scientific articles putting limits to the number of analyses that can be presented in a paper; and (3) the greater amounts of ecological knowledge and labour required for applying high-informative measures or approaches to several taxonomic groups. There is a general agreement in the scientific community that multiple taxonomic groups should be studied to obtain reliable estimates of the effects of a given human intervention on biodiversity (Barlow et al. 2007; Brown and Williams 2016). In our evaluation, a few of the studies consistently used high-informative measures while encompassing several taxonomic groups and covering a large geographical scale (e.g., Gibson et al. 2011; Fedrowitz et al. 2014; Curran et al. 2014; Newbold et al. 2014), showing that with some effort, high-informative measures can be used even in wide-scope studies.

The prevalence of studies based on low-informative measures increased over time. To test whether that could be an effect of a temporal increase in the breadth of taxonomic scope (i.e., whether the study encompassed one or several different taxonomic groups), we fitted a new GLM a posteriori, with taxonomic scope as a response and year as a predictor. We found that the prevalence of wide-scope studies increased over time $(P=0.029$; Online Resource 3). Hence, the increased prevalence of low-informative measures over time could possibly be explained by an increase in the breadth of the taxonomic scope of the studies.

In accordance with our expectations, the results suggest that good knowledge of the studied taxonomic group allows more informative measures to be used, as illustrated by the trend for a higher proportion of high-informative measures in vertebrates than fungi. However, this pattern does not seem to always hold. Against our expectations, insects had the highest prevalence of high-informative measures among all the taxonomic subgroups, in spite of the fact that they are still poorly known in many parts of the world. This is partly due to some insect families, such as Carabids (Coleoptera), being widely used as indicators of land-use change, allowing high-informative measures to be used. However, we believe that with more effort, more refined measures can be used for most, if not all, taxonomic groups. On the other hand, meta-analyses belonging to the category 'unspecified/ other invertebrates' were characterized by a higher prevalence of low-informative response measures, as expected from the fact that they may be lesser known than insects. Nevertheless, relatively high proportion of analyses addressing birds and mammals were evaluated as low-informative, in spite of their well-known ecology which should allow the use of high-informative measures. This result can be partly explained by differences in the scopes of the studies: a large proportion of the studies including birds or mammals had a broad taxonomic scope including several groups ( $c f$. Online Resource 4), possibly restricting the use of high-informative measure.

\section{Towards more informative approaches}

Santini et al. (2017) suggested that monitoring of species presences and their respective abundances is essential for primary biodiversity studies. To further guide future metaanalyses, we suggest that along with simple measures of gross species richness and abundance, more refined approaches to measuring biodiversity response should be used both in meta-analyses and in primary studies. Here, drawing on the reviewed meta-analyses and 

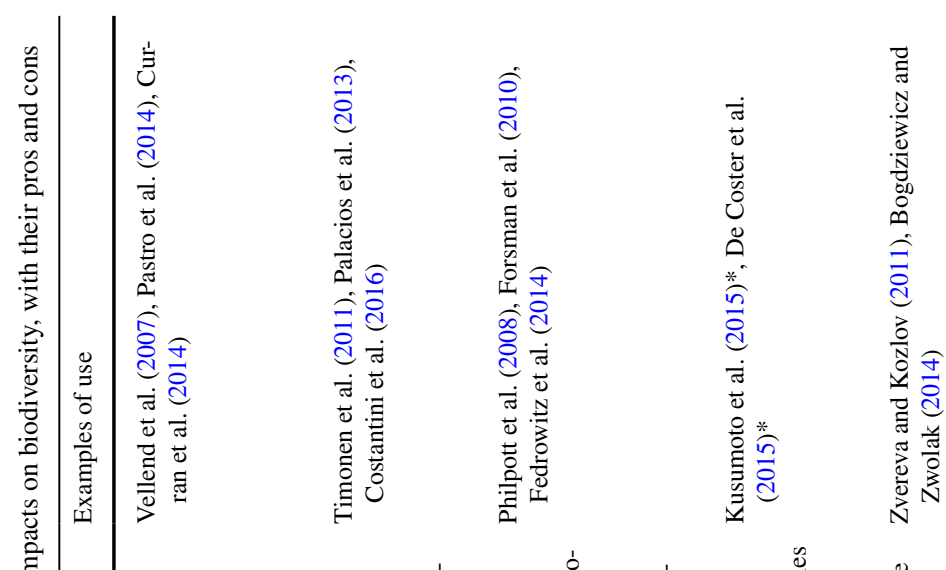

.

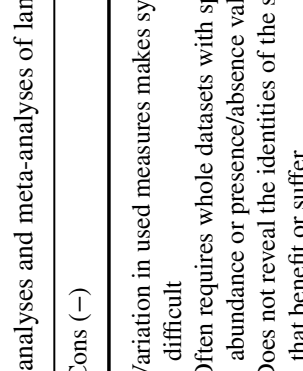

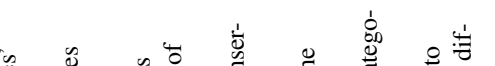

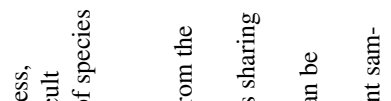
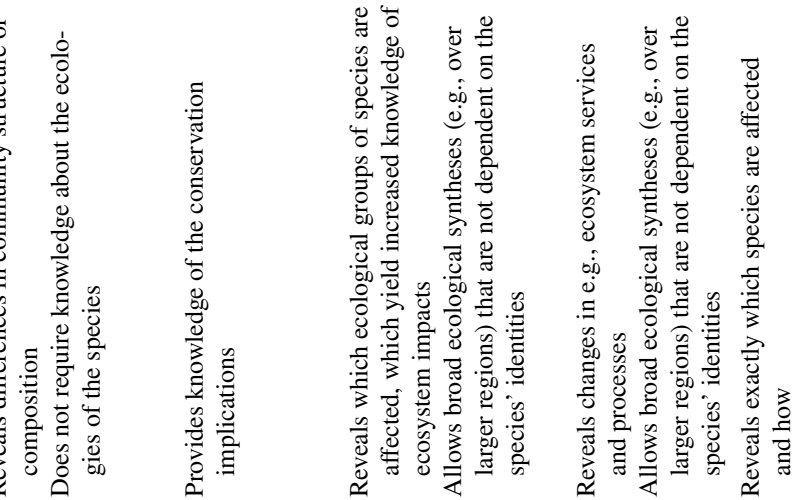

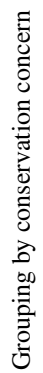

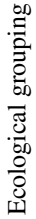
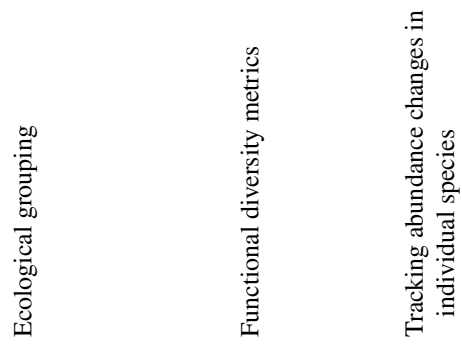
the broader literature on the topic, we describe possible high-informative approaches and present a synthesis of their pros and cons (Table 3).

\section{$\beta$ diversity measures}

$\beta$ diversity measures comprise numerous approaches quantifying compositional heterogeneity of species communities in space or time. Examples include indices of (dis)similarity, measures of turnover and partitioning of diversity (Magurran 2004; Socolar et al. 2016). The measurement of $\beta$ diversity is a huge and expanding field in ecology, and in-depth discussion of the differences in measures is beyond the scope of this study. For overviews and discussions of the topic, we refer the readers to the comprehensive reviews of Anderson et al. (2011) and Socolar et al. (2016).

In the primary literature, the use of $\beta$ diversity measures has increased almost exponentially during the 2000s (Anderson et al. 2011). Still, in our evaluation, only 10 out of 89 studies used $\beta$ diversity measures. Performing meta-analyses based directly on the $\beta$ diversity metrics presented in primary studies is often problematic due to the heterogeneity in the reported metrics among studies. Therefore, meta-analysts will often have to re-analyse the underlying species data provided in the different primary studies according to a common framework. The use of $\beta$ diversity measures in meta-analyses may hence be hindered by a lack of species abundance or occurrence data in primary studies.

When achievable, approaches based on $\beta$ diversity can yield important insights to complement analyses of e.g., total species richness measures. For example, Curran et al. (2014) calculated standardized response ratios for similarity indices for thousands of old-growthsecondary forest comparisons, and found out that while species richness in secondary forest converges to old-growth forest values within a century, the community composition and structure remain distinct even for thousands of years. Similar discrepancies were found in many other studies that used both species richness and $\beta$ diversity metrics as measures of biodiversity (e.g., Nichols et al. 2007; Palacios et al. 2013; Pastro et al. 2014).

In our evaluation, the most used $\beta$ diversity measures were binary Jaccard (Anand et al. 2010; Palacios et al. 2013; Thompson et al. 2016) or Sørensen (Pastro et al. 2014; Curran et al. 2014) measures, and a quantitative Morisita-Horn measure (Nichols et al. 2007; Curran et al. 2014).

A limitation of $\beta$ diversity measures is that even if they may show the existence of a difference in community composition or structure as a result of land-use, they do not provide knowledge about which species benefit and which suffer (Socolar et al. 2016). Furthermore, for example Sørensen similarity index does not reveal proportionally minor, but ecologically important changes caused by e.g., an increase or decrease of ecologically significant species (Santini et al. 2017). Therefore, ideally, $\beta$ diversity measures should be accompanied by additional measures providing more refined information about the nature of the change. The approaches or measures presented in the following sections can be used to describe the changes in composition or structure in more detail.

\section{Grouping by conservation concern}

Lists of species of conservation concern (e.g., red lists, annexes to international directives, lists of declining species) can be used to address effects of land-use on species belonging to different threat categories (e.g., red-listed vs. least-concern species). The approach was rarely used in the papers that we reviewed: only nine of the 92 studies addressed 
conservation status in their analyses. A major recurring challenge in studies of land-use impacts on biodiversity is the insufficient amount of data about red-listed species. Indeed, such species are often rare and hence the analyses of land-use impacts on such species suffer from too low sample size (Martikainen and Kouki 2003). One way to overcome the problem is to pool the data about species of conservation concern over taxonomic groups. For example, Timonen et al. (2011) used the comprehensive red-lists of Finland, Sweden and Norway to assess the abundance of red-listed species in woodland key habitats, pooling vascular plants, bryophytes, lichens, polypores and beetles. When data are sufficiently detailed, the approach can be used to e.g., evaluate the goodness of conservation areas, whether the species that benefit are the ones that are originally targeted (i.e., species of conservation concern) (Coetzee et al. 2014). Finally, an additional key challenge for the use of this approach is that many developing countries lack national red lists, and many others have red-lists that are restricted to or heavily biased toward better-known taxonomic groups.

\section{Ecological grouping and functional diversity measures}

Clearly the most commonly used high-informative measure in our evaluation was to classify species into ecologically or functionally defined groups and analyze species richness and/or abundance separately for each group. Grouping species according to their habitat requirements, ecological functions or foraging guilds may reveal important changes in community structure that may be hidden in total species richness or $\beta$ diversity measures. Even a simple division into forest/non-forest species (Philpott et al. 2008; De Beenhouwer et al. 2013; Fedrowitz et al. 2014; Burivalova et al. 2014) or specialist/generalist species (Gibson et al. 2011; Newbold et al. 2014; Thompson et al. 2016) may provide critical information on sensitive species groups and thereby contribute to improved ecosystem management or conservation planning.

Grouping species into relevant niches or categories is not always an easy task (Fontaine and Kennedy 2012). Hence, this approach demands good knowledge of the species' ecologies. The high level of ecological knowledge on birds, mammals, and some plant groups facilitates the use of ecological grouping. However, this approach can also be applicable to some insect groups that are relatively well known. For example, in a meta-analysis of the effects of urbanization on ground beetles, Martinson and Raupp (2013) classified the species according to their functional traits and showed that large-bodied, forest specialist predator species were most negatively affected by urbanization.

The existence of established and globally accepted terminologies is beneficial for an efficient application of ecological grouping. Good examples are the classification of bird species into foraging guilds (Gray et al. 2007; Forsman et al. 2010; Hill et al. 2011), or the division of forest species into saproxylic (deadwood dependent) and non-saproxylic species (Seibold et al. 2015). The grouping approach is rather easy to use when grouping standards are well established, but more demanding when a new classification is to be developed. Hence, we strongly recommend authors of primary studies to provide locally relevant summaries of the species' ecologies (e.g., classifications into forest specialists/generalists) when species lists are included as supplementary material. An additional challenge posed by the approach is that it requires much data to ensure that sufficient sample size is attained within the different groups that are separately analyzed. Moreover, phylogenies of the species should ideally be accounted for, as the species belonging to a given functional guild 
may be related and thus may not be independent from each other (Chiarucci et al. 2011; Chamberlain et al. 2012).

A second approach accounting for the ecologies of the species is to use functional diversity metrics (Petchey and Gaston 2002). Measures of functional diversity quantify the distribution of functional traits (e.g., physical, biochemical, behavioral, temporal or phenological traits) in species communities, and may thus provide information about the impacts of land use on ecosystem services, functions or processes. For in-depth reviews of the topic, we refer the reader to Hillebrand and Matthiessen (2009) and Cadotte et al. (2011). To our surprise, the method was not used in any of the meta-analyses included in our review, in spite of the rapidly increasing interest in functional diversity of communities (Cadotte et al. 2011). Typically, functional diversity metrics rely on classified or quantitative trait measures, often consider multivariate traits and may also include species abundances to account for dissimilarity, evenness and divergence of functional diversity (see Hillebrand and Matthiessen (2009) and references therein). The resulting diversity of reported measures in primary studies may cause problems in performing meta-analyses, unless-once againpublished datasets with ecological trait or life-history information allow the meta-analysts to perform the analyses in a unified way (see e.g., Lindenmayer et al. 2015). However, functional diversity metrics are insensitive to e.g., species extirpations, and thus should not be used as an only measure of biodiversity, but to bring additional information on change in community structure (see e.g., Santini et al. 2017).

\section{Tracking abundance changes in individual species}

A very detailed and high-informative measure of changes in biodiversity is to track effects on the abundances of individual species. In our review of published meta-analyses, the reporting of individual species' responses was mostly used for bird or mammal communities. Only two meta-analyses diverged from the bird-mammal pattern: Martinson and Raupp (2013) (Carabid beetles) and Zvereva and Kozlov (2011) (bryophytes).

While measures that pool species into groups necessarily result in some level of information loss, studies analyzing the responses of all individual species present a complete but often complex picture. Therefore, an analysis of the responses of individual species should be accompanied by additional analyses facilitating a synthesis of the ecological effects (e.g., $\beta$ diversity measures summarizing species turnover, or ecological grouping summarizing effects on different guilds). If used alone, this approach puts special responsibility on the authors to guide the readers as to the ecological or conservation implications of the effects on the different species (because the readers cannot be expected to have good knowledge of all individual species). Species-specific analyses provide very detailed information that may prove to be extremely important for conservation planning in the future. However, the method suits best for restricted species groups or smaller geographical areas.

\section{Recommendations for the future}

One reason for the high prevalence of low-informative measures lies in the types of measures reported by the primary studies underlying the meta-analyses. To improve knowledge in terms of applicability to conservation ecology and land-use management, future metaanalyses should use measures that better account for compositional or ecological changes in the communities, such as the ones presented above. As a foundation for this, primary 
studies should always use several measures of biodiversity and, as a minimum requirement, report species lists with abundances from which various community attributes can be derived for later use in meta-analyses.

Acknowledgements This work was supported by Kempe Foundation (SMK-1339).We thank four anonymous reviewers for valuable comments for the manuscript.

Open Access This article is distributed under the terms of the Creative Commons Attribution 4.0 International License (http://creativecommons.org/licenses/by/4.0/), which permits unrestricted use, distribution, and reproduction in any medium, provided you give appropriate credit to the original author(s) and the source, provide a link to the Creative Commons license, and indicate if changes were made.

\section{References}

Anand MO, Krishnaswamy J, Kumar A, Bali A (2010) Sustaining biodiversity conservation in human-modified landscapes in the Western Ghats: remnant forests matter. Biol Conserv 143:2363-2374. https:// doi.org/10.1016/j.biocon.2010.01.013

Anderson MJ, Crist TO, Chase JM et al (2011) Navigating the multiple meanings of $\beta$ diversity: a roadmap for the practicing ecologist: roadmap for beta diversity. Ecol Lett 14:19-28. https://doi.org/10.111 1/j.1461-0248.2010.01552.x

Balvanera P, Pfisterer AB, Buchmann N et al (2006) Quantifying the evidence for biodiversity effects on ecosystem functioning and services: biodiversity and ecosystem functioning/services. Ecol Lett 9:1146-1156. https://doi.org/10.1111/j.1461-0248.2006.00963.x

Barlow J, Gardner TA, Araujo IS et al (2007) Quantifying the biodiversity value of tropical primary, secondary, and plantation forests. Proc Natl Acad Sci USA 104:18555-18560. https://doi.org/10.1073/ pnas. 0703333104

Bates D, Mächler M, Bolker B, Walker S (2015) Fitting linear mixed-effects models using lme4. J Stat Softw. https://doi.org/10.18637/jss.v067.i01

Bogdziewicz M, Zwolak R (2014) Responses of small mammals to clear-cutting in temperate and boreal forests of Europe: a meta-analysis and review. Eur J For Res 133:1-11. https://doi.org/10.1007/s1034 2-013-0726-X

Brown ED, Williams BK (2016) Ecological integrity assessment as a metric of biodiversity: are we measuring what we say we are? Biodivers Conserv 25:1011-1035. https://doi.org/10.1007/s10531-016-1111-0

Burivalova Z, Şekercioğlu ÇH, Koh LP (2014) Thresholds of logging intensity to maintain tropical forest biodiversity. Curr Biol 24:1893-1898. https://doi.org/10.1016/j.cub.2014.06.065

Cadotte MW, Carscadden K, Mirotchnick N (2011) Beyond species: functional diversity and the maintenance of ecological processes and services: functional diversity in ecology and conservation. J Appl Ecol 48:1079-1087. https://doi.org/10.1111/j.1365-2664.2011.02048.x

Chamberlain SA, Hovick SM, Dibble CJ et al (2012) Does phylogeny matter? Assessing the impact of phylogenetic information in ecological meta-analysis. Ecol Lett 15:627-636. https://doi.org/10.111 1/j.1461-0248.2012.01776.x

Chaudhary A, Burivalova Z, Koh LP, Hellweg S (2016) Impact of forest management on species richness: global meta-analysis and economic trade-offs. Sci Rep 6:23954. https://doi.org/10.1038/srep23954

Chiarucci A, Bacaro G, Scheiner SM (2011) Old and new challenges in using species diversity for assessing biodiversity. Philos Trans R Soc B Biol Sci 366:2426-2437. https://doi.org/10.1098/rstb.2011.0065

Coetzee BWT, Gaston KJ, Chown SL (2014) Local scale comparisons of biodiversity as a test for global protected area ecological performance: a meta-analysis. PLoS ONE 9:e105824. https://doi.org/10.1371/ journal.pone. 0105824

Costantini D, Edwards DP, Simons MJP (2016) Life after logging in tropical forests of Borneo: a metaanalysis. Biol Conserv 196:182-188. https://doi.org/10.1016/j.biocon.2016.02.020

Curran M, Hellweg S, Beck J (2014) Is there any empirical support for biodiversity offset policy? Ecol Appl 24:617-632. https://doi.org/10.1890/13-0243.1

De Beenhouwer M, Aerts R, Honnay O (2013) A global meta-analysis of the biodiversity and ecosystem service benefits of coffee and cacao agroforestry. Agric Ecosyst Environ 175:1-7

De Coster G, Banks-Leite C, Metzger JP (2015) Atlantic forest bird communities provide different but not fewer functions after habitat loss. Proc R Soc B 282:20142844. https://doi.org/10.1098/rspb.2014.2844 
Dornelas M (2010) Disturbance and change in biodiversity. Philos Trans R Soc B 365:3719-3727. https:// doi.org/10.1098/rstb.2010.0295

Dornelas M, Gotelli NJ, McGill B et al (2014) Assemblage Time series reveal biodiversity change but not systematic loss. Science 344:296-299. https://doi.org/10.1126/science.1248484

Duguid MC, Ashton MS (2013) A meta-analysis of the effect of forest management for timber on understory plant species diversity in temperate forests. For Ecol Manag 303:81-90

Fedrowitz K, Koricheva J, Baker SC et al (2014) Can retention forestry help conserve biodiversity? A meta-analysis. J Appl Ecol 51:1669-1679

Fontaine JB, Kennedy PL (2012) Meta-analysis of avian and small-mammal response to fire severity and fire surrogate treatments in U.S. Fire-prone forests. Ecol Appl 22:1547-1561

Forsman JT, Reunanen P, Jokimäki J, Mönkkönen M (2010) The effects of small-scale disturbance on forest birds: a meta-analysis. Can J For Res 40:1833-1842

Gerisch M, Agostinelli V, Henle K, Dziock F (2012) More species, but all do the same: contrasting effects of flood disturbance on ground beetle functional and species diversity. Oikos 121:508-515. https://doi.org/10.1111/j.1600-0706.2011.19749.x

Gibson L, Lee TM, Koh LP et al (2011) Primary forests are irreplaceable for sustaining tropical biodiversity. Nature 478:378-381. https://doi.org/10.1038/nature10425

Gray MA, Baldauf SL, Mayhew PJ, Hill JK (2007) The response of avian feeding guilds to tropical forest disturbance. Conserv Biol 21:133-141. https://doi.org/10.1111/j.1523-1739.2006.00557.x

Gurevitch J, Koricheva J, Nakagawa S, Stewart G (2018) Meta-analysis and the science of research synthesis. Nature 555:175-182. https://doi.org/10.1038/nature25753

Hill JK, Gray MA, Khen CV et al (2011) Ecological impacts of tropical forest fragmentation: how consistent are patterns in species richness and nestedness? Philos Trans R Soc B 366:3265-3276. https ://doi.org/10.1098/rstb.2011.0050

Hillebrand H, Matthiessen B (2009) Biodiversity in a complex world: consolidation and progress in functional biodiversity research: consolidation and progress in BDEF research. Ecol Lett 12:14051419. https://doi.org/10.1111/j.1461-0248.2009.01388.x

Jaunatre R, Buisson E, Muller I et al (2013) New synthetic indicators to assess community resilience and restoration success. Ecol Indic 29:468-477. https://doi.org/10.1016/j.ecolind.2013.01.023

Jurasinski G, Retzer V, Beierkuhnlein C (2009) Inventory, differentiation, and proportional diversity: a consistent terminology for quantifying species diversity. Oecologia 159:15-26. https://doi. org/10.1007/s00442-008-1190-z

Koricheva J, Gurevitch J, Mengersen K (2013) Handbook of meta-analysis in ecology and evolution. Princeton University Press, Princeton

Kusumoto B, Shiono T, Miyoshi M et al (2015) Functional response of plant communities to clearcutting: management impacts differ between forest vegetation zones. J Appl Ecol 52:171-180. https:// doi.org/10.1111/1365-2664.12367

Lindenmayer D, Blanchard W, Tennant P et al (2015) Richness is not all: how changes in avian functional diversity reflect major landscape modification caused by pine plantations. Divers Distrib 21:836-847. https://doi.org/10.1111/ddi.12328

Lortie CJ, Stewart G, Rothstein H, Lau J (2015) How to critically read ecological meta-analyses. Res Synth Methods 6:124-133. https://doi.org/10.1002/jrsm.1109

Magurran AE (2004) Measuring biological diversity. Blackwell Pub, Malden

Martikainen P, Kouki J (2003) Sampling the rarest: threatened beetles in boreal forest biodiversity inventories. Biodivers Conserv 12:1815-1831

Martinson HM, Raupp MJ (2013) A meta-analysis of the effects of urbanization on ground beetle communities. Ecosphere 4:60

Murphy GEP, Romanuk TN (2016) Data gaps in anthropogenically driven local-scale species richness change studies across the Earth's terrestrial biomes. Ecol Evol 6:2938-2947. https://doi. org/10.1002/ece3.2004

Newbold T, Hudson LN, Phillips HRP et al (2014) A global model of the response of tropical and subtropical forest biodiversity to anthropogenic pressures. Proc R Soc B 281:20141371. https://doi. org/10.1098/rspb.2014.1371

Nichols E, Larsen T, Spector S et al (2007) Global dung beetle response to tropical forest modification and fragmentation: a quantitative literature review and meta-analysis. Biol Conserv 137:1-19. https ://doi.org/10.1016/j.biocon.2007.01.023

Palacios CP, Agueero B, Simonetti JA (2013) Agroforestry systems as habitat for herpetofauna: is there supporting evidence? Agrofor Syst 87:517-523. https://doi.org/10.1007/s10457-012-9571-Z

Pastro LA, Dickman CR, Letnic M (2014) Fire type and hemisphere determine the effects of fire on the alpha and beta diversity of vertebrates: a global meta-analysis. Glob Ecol Biogeogr 23:1146-1156 
Petchey OL, Gaston KJ (2002) Functional diversity (FD), species richness and community composition. Ecol Lett 5:402-411. https://doi.org/10.1046/j.1461-0248.2002.00339.x

Philpott SM, Arendt WJ, Armbrecht I et al (2008) Biodiversity loss in Latin American coffee landscapes: review of the evidence on ants, birds, and trees. Conserv Biol 22:1093-1105. https://doi.org /10.1111/j.1523-1739.2008.01029.x

Putz FE, Zuidema PA, Synnott T et al (2012) Sustaining conservation values in selectively logged tropical forests: the attained and the attainable: sustaining tropical forests with forestry. Conserv Lett 5:296303. https://doi.org/10.1111/j.1755-263X.2012.00242.x

R Development Core Team (2015) R: a language and environment for statistical computing. R Foundation for Statistical Computing, Vienna

Santini L, Belmaker J, Costello MJ et al (2017) Assessing the suitability of diversity metrics to detect biodiversity change. Biol Conserv 213:341-350. https://doi.org/10.1016/j.biocon.2016.08.024

Seibold S, Bässler C, Brandl R et al (2015) Experimental studies of dead-wood biodiversity-a review identifying global gaps in knowledge. Biol Conserv 191:139-149. https://doi.org/10.1016/j.bioco n.2015.06.006

Shimadzu H, Dornelas M, Magurran AE (2015) Measuring temporal turnover in ecological communities. Methods Ecol Evol 6:1384-1394. https://doi.org/10.1111/2041-210X.12438

Socolar JB, Gilroy JJ, Kunin WE, Edwards DP (2016) How should beta-diversity inform biodiversity conservation? Trends Ecol Evol 31:67-80. https://doi.org/10.1016/j.tree.2015.11.005

Supp SR, Ernest SKM (2014) Species-level and community-level responses to disturbance: a cross-community analysis. Ecology 95:1717-1723. https://doi.org/10.1890/13-2250.1

Thompson ME, Nowakowski AJ, Donnelly MA (2016) The importance of defining focal assemblages when evaluating amphibian and reptile responses to land use. Conserv Biol 30:249-258. https://doi. org/10.1111/cobi.12637

Timonen J, Gustafsson L, Kotiaho JS, Mönkkönen M (2011) Hotspots in cold climate: conservation value of woodland key habitats in boreal forests. Biol Conserv 144:2061-2067. https://doi.org/10.1016/j.bioco n.2011.02.016

Vellend M, Verheyen K, Flinn KM et al (2007) Homogenization of forest plant communities and weakening of species-environment relationships via agricultural land use. J Ecol 95:565-573. https://doi.org/10.1 111/j.1365-2745.2007.01233.x

Vellend M, Baeten L, Myers-Smith IH et al (2013) Global meta-analysis reveals no net change in local-scale plant biodiversity over time. Proc Natl Acad Sci USA 110:19456-19459

Whittaker RJ, Willis KJ, Field R (2001) Scale and species richness: towards a general, hierarchical theory of species diversity: towards a general theory of diversity. J Biogeogr 28:453-470. https://doi.org/10.104 6/j.1365-2699.2001.00563.x

Zvereva EL, Kozlov MV (2011) Impacts of industrial polluters on bryophytes: a meta-analysis of observational studies. Water Air Soil Pollut 218:573-586. https://doi.org/10.1007/s11270-010-0669-5 